\title{
A!
}

This is an electronic reprint of the original article.

This reprint may differ from the original in pagination and typographic detail.

Scotti, Gianmario; Kanninen, P.; Mäkinen, Mika; Kallio, T.; Franssila, S.

\section{Silicon nanograss as micro fuel cell gas diffusion layer}

\author{
Published in: \\ MICRO AND NANO LETTERS
}

DOI:

$10.1049 / \mathrm{mnl} .2010 .0122$

Published: 01/01/2010

Document Version

Peer reviewed version

Please cite the original version:

Scotti, G., Kanninen, P., Mäkinen, M., Kallio, T., \& Franssila, S. (2010). Silicon nanograss as micro fuel cell gas diffusion layer. MICRO AND NANO LETTERS, 5(6), 382-385. https://doi.org/10.1049/mnl.2010.0122

This material is protected by copyright and other intellectual property rights, and duplication or sale of all or part of any of the repository collections is not permitted, except that material may be duplicated by you for your research use or educational purposes in electronic or print form. You must obtain permission for any other use. Electronic or print copies may not be offered, whether for sale or otherwise to anyone who is not an authorised user. 


\section{SILICON NANOGRASS AS MICRO FUEL CELL GAS DIFFUSION LAYER}

Gianmario Scotti ${ }^{* 1,3}$, Petri Kanninen ${ }^{2}$, Maija Mäkinen ${ }^{3}$, Tanja Kallio ${ }^{2}$, and Sami Franssila ${ }^{3}$

${ }^{1}$ Department of Micro and Nanosciences, Aalto University School of Science and

Technology, P.O. Box 13500, 00076 Aalto, Espoo, FINLAND

${ }^{2}$ Department of Chemistry, Aalto University School of Science and Technology, P. O. Box 16100, 00076 Aalto, Espoo, FINLAND

${ }^{3}$ Department of Materials Science and Engineering, Aalto University School of Science and Technology, P. O. Box 16200, 00076 Aalto, Espoo, FINLAND

* Corresponding author: Tel. +358 50 3632739, Fax. +358 9470 26080, e-mail: gianmario.scotti@.tkk.fi, (G. Scotti)

\section{ABSTRACT}

This paper describes a microfabricated fuel cell (MFC) which uses hydrogen as fuel and a polymer proton exchange membrane (PEM) as electrolyte. Microchannels have been etched in highly conductive silicon, and silicon nanograss (black silicon) has been formed on the surface, thus implementing a support structure, current collector, flowfield and gas diffusion layer (GDL) all in one. The devices are thus very compact, simple to fabricate and low cost. The MFC presented here shows promising performance of $70 \mathrm{~mW} \mathrm{~cm}-2$ power density and $100 \mathrm{~mA} \mathrm{~cm}{ }^{-2}$ current density at $0.7 \mathrm{~V}$, comparable to that of other similar monolithic devices found in literature.

\section{KEYWORDS}

Micro fuel cell, silicon, nanograss, etching, polymer electrolyte, MEMS, gas diffusion layer. 


\section{INTRODUCTION}

In recent years there has been a growing interest in replacing conventional lithium ion batteries with fuel cells as power sources for portable electronic devices (laptops, handheld cameras, mobile phones etc.), to achieve higher energy densities [1]. Microfabrication technologies enable highly integrated, compact micro fuel cells. The most promising fuel candidates are hydrogen and methanol. Many of the micro fuel cells are made from silicon because it is the material for which there is most microfabrication expertise: thin film processes (evaporation, sputtering, chemical vapor deposition, oxidation, etc.) and dry and wet etching chemistries are implemented and welloptimized for silicon as a substrate. Furthermore, silicon is hard, durable and has reasonable chemical and thermal stability. The electrochemical properties of silicon are extensively researched and documented.

In this work, we show how silicon microfabrication technologies enable us to integrate flow channels, electrodes, gas diffusion layer (GDL) and current collection into a single structure, with a very small number of fabrication steps. Due to the integration of the GDL with the current collector and flowfield, and the lack of many metallization or other layers (mechanical support, current collector, insulation, gas distribution, electrical distribution, etc.), the device is very compact (very thin) which can lead to high volumetric power densities. Other authors [2-6] have also integrated macroporous silicon (IUPAC term for pores larger than $50 \mathrm{~nm}$ ) GDL, the flowfield and the current collector into a monolithic silicon unit using microfabrication techniques. Our device, however, shows that integration can be carried much further, while simultaneously simplifying the fabrication process. We use the term "flowfield body" to denote the structure consisting of the current collector, the flowfield and the gas diffusion layer. This distinguishes it from electrodes, which in our case are part of the membrane-electrode assembly (MEA) and consist of carbon black with platinum nanoparticles, spray-painted onto the polymer electrolyte membrane (PEM). 


\section{EXPERIMENTAL}

\section{$\underline{\text { Construction }}$}

We have designed and fabricated three devices with the main difference between them being the profile (crested and rectangular) and topology (straight and serpentine grooves, and pillars) of the flowfield channels. Fig. 1 depicts the construction of the flowfield bodies (a and $b$ ), and the assembly of a fuel cell (c), composed of two flowfield bodies with a PEM (Nafion ${ }^{\circledR}$ ) sandwiched between them. The gas inlet holes introduce the reactant gases into the flowfield and the GDL.
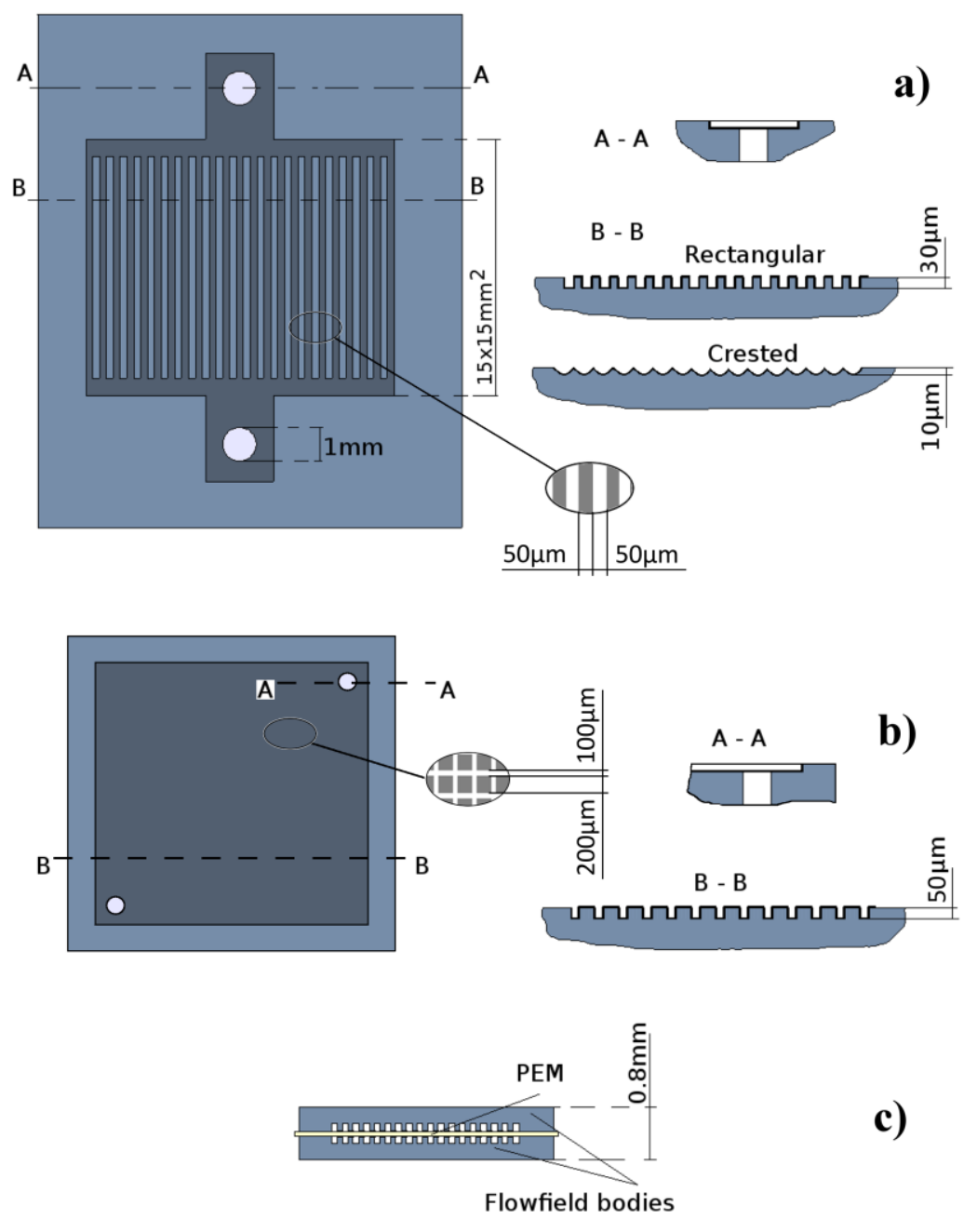

Figure 1: Construction of a single flowfield body (top views and cross sections) for the symmetric a) and diagonal flow design b), and assembly of a fuel cell, c). 


\section{$\underline{\text { Fabrication }}$}

A detailed description of the fabrication of a fuel cell with rectangular flowfield channels will be presented. The main difference in fabrication in the case of the crested profile channels is an isotropic reactive ion etching (RIE) step. More information on the crested profile flowfield fabrication can be found in [7].

The starting point for the flowfield body is a highly boron-doped ( $\rho=0.01 \Omega \mathrm{cm}$ ), thermally oxidized silicon wafer. The main fabrication steps for the flowfield bodies are presented in Fig. 2: the thermally oxidized wafer (oxide thickness of about $300 \mathrm{~nm}$ ) is patterned with photolithography and BHF etching (2a) to delimit the area affected by silicon nanograss formation later on. Thin resist (AZ $1505 \AA, 0.5 \mu \mathrm{m}$ thick with spinning at $4000 \mathrm{RPM}$ ) is spun and patterned, to function as an etch mask (2b), followed by a silicon deep RIE (DRIE) etch step performed in a cryogenic ICP RIE (Oxford Instruments Plasmalab® System 100) in $\mathrm{SF}_{6} / \mathrm{O}_{2}$ (etch parameters: ICP 2kW, CCP 3W, SF 6 flow $100 \mathrm{sccm}, \mathrm{O}_{2}$ flow $15 \mathrm{sccm}$, pressure $10 \mathrm{mTorr}$, temperature $\left.-110^{\circ} \mathrm{C}\right)(2 \mathrm{c})$. Processing under these conditions results in $\sim 30 \mu \mathrm{m}$ deep channels after 5 minutes of etching and $50 \mu \mathrm{m}$ tall square pillars after 7.5 minutes. On the backside of the wafer a $200 \mathrm{~nm}$ aluminum layer is deposited by sputtering (Plasmalab ${ }^{\circledR}$ System 400) and patterned with commercial $\mathrm{H}_{3} \mathrm{PO}_{4}$-based wet etchant. This layer acts as an etch mask for through-wafer DRIE etching for the gas inlets (2d). The inlet etching process is identical to flowfield etching process. Finally, nanograss (black silicon) is formed by plasma etching under passivating conditions (ICP $1 \mathrm{~kW}, \mathrm{CCP} 2 \mathrm{~W}, \mathrm{SF}_{6}$ flow $40 \mathrm{sccm}, \mathrm{O}_{2}$ flow 18 sccm, $\left.\mathrm{p}=10 \mathrm{mTorr}, \mathrm{T}=-120^{\circ} \mathrm{C}, \mathrm{t}=10 \mathrm{~min}\right)(3 \mathrm{e})$. on the area (on the top side) unprotected by thermal oxide. 


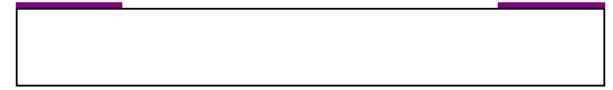

(a) Pattern $\mathrm{SiO}_{2}$ to define the black silicon area.

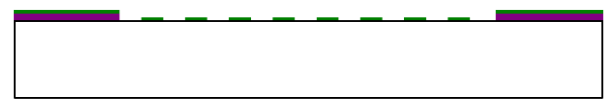

(b) Pattern the mask for the flowfield.

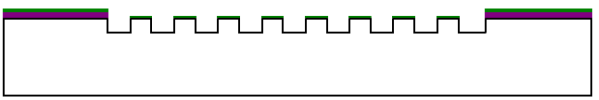

(c) RIE of flowfield, 30-50 $\mu \mathrm{m}$ deep.

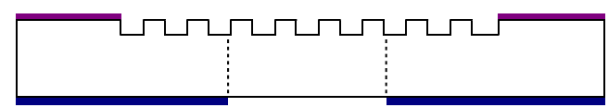

(d) Backside gas inlet etch through Al mask.

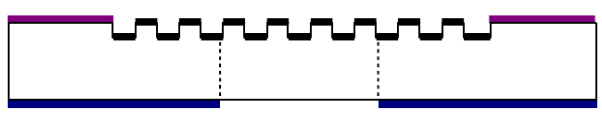

(e) Black silicon formation and metalization.

Figure 2: Process flow for the fabrication of a square profile flowfield body with gas inlets, flowfield and gas diffusion layer. Details are provided in the text.

SEM and AFM micrographs of the resulting silicon nanograss are shown in Fig. 3. As the last microfabrication step a thin metallization layer (30 $\mathrm{nm}$ of chromium or $30 \mathrm{~nm}$ platinum) is sputtered over the nanograss to improve electrical conductivity. Fig. 4 shows SEM micrographs of the three MFC flowfields. 


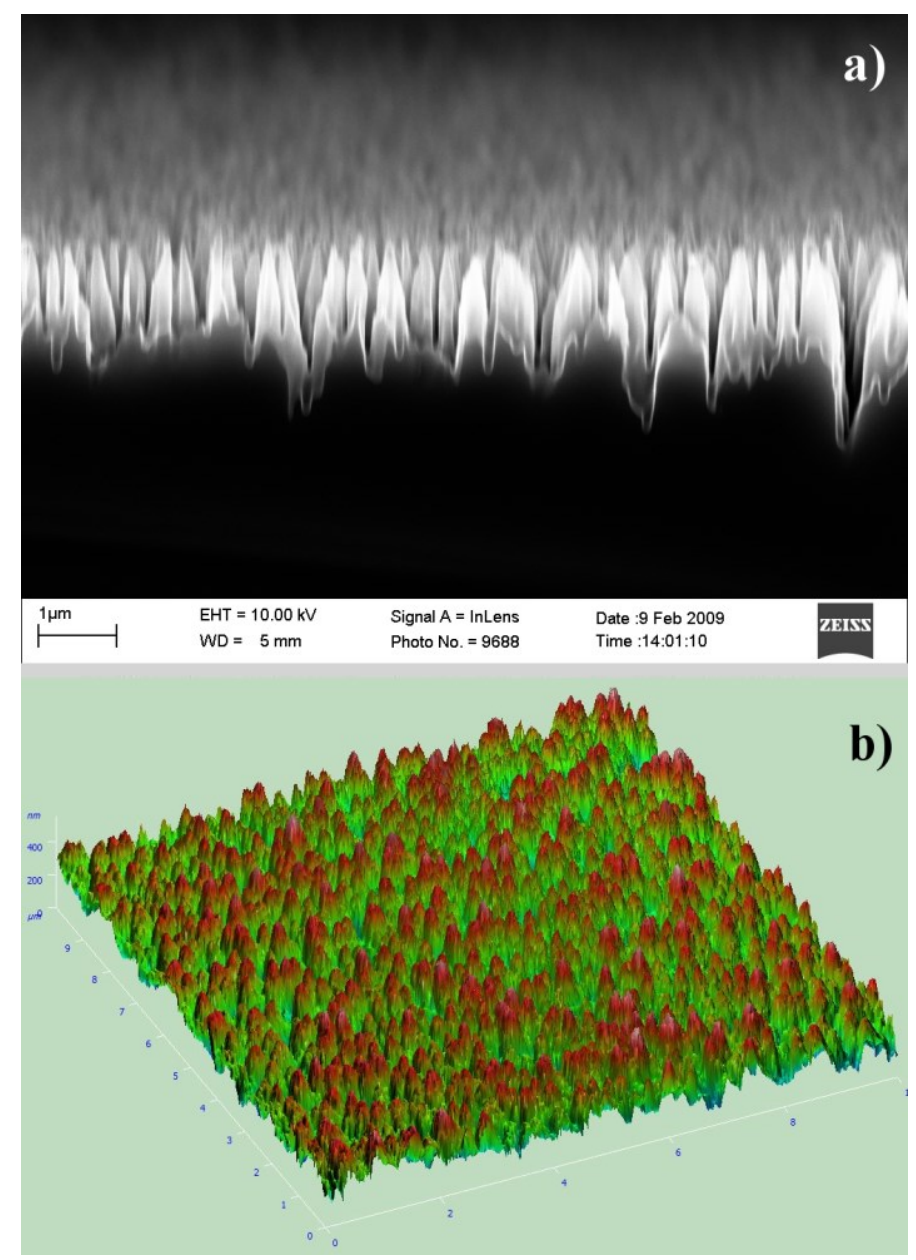

Figure 3. a) SEM and b) AFM micrographs of silicon nanograss, used as a GDL for the fuel cells in this paper. 


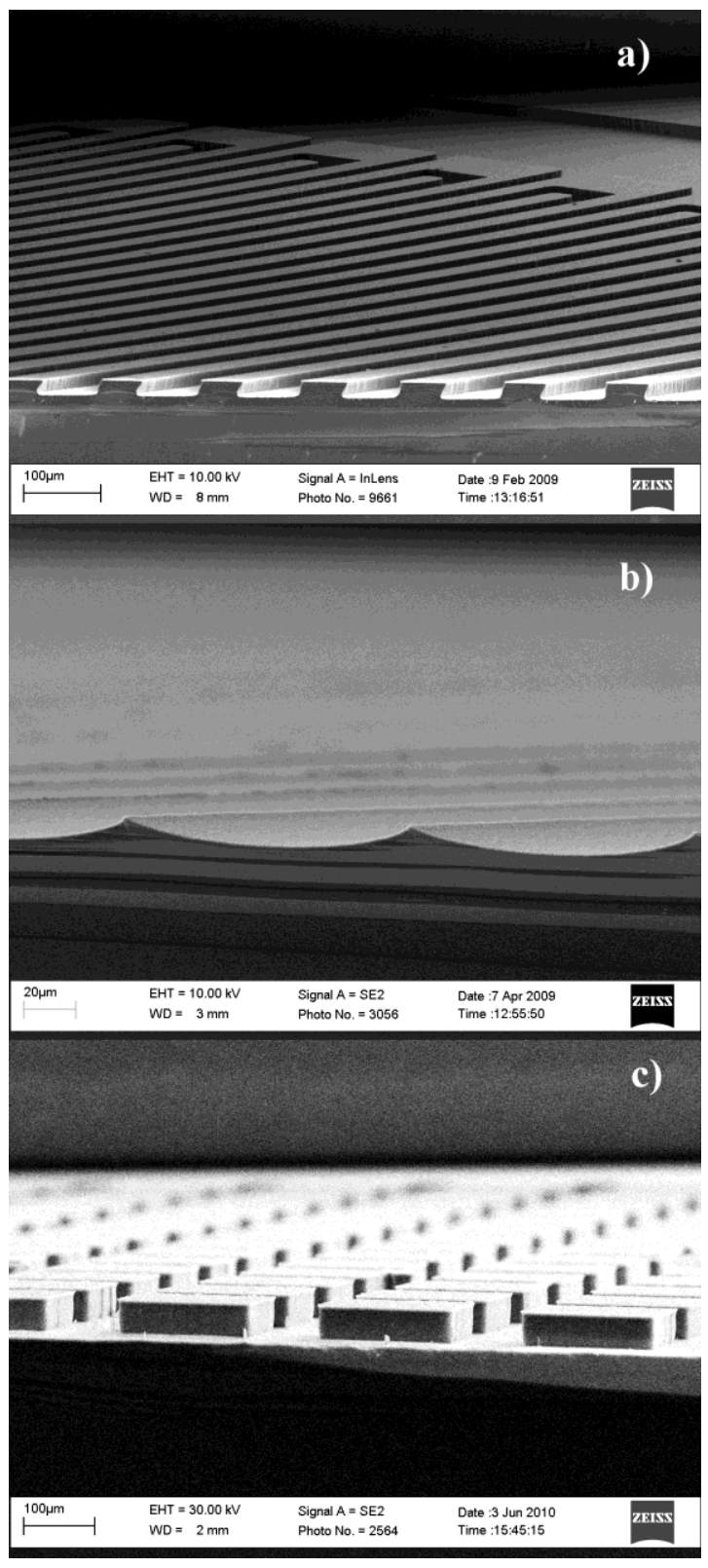

Figure 4: SEM micrographs of a) square-profile, b) crested profile and c) rectangular pillar flowfield. Note the serpentine topology of the channels in a). 
Table 1 summarizes the differences between the three flowfields studied in this paper.

Table 1: Summary of flowfield geometries.

\begin{tabular}{|l|c|c|c|}
\hline Flowfield type & Crested profile & Rectangular profile & Rectangular pillars \\
\hline Channel depth $(\mu \mathrm{m})$ & 10 & 30 & 50 \\
\hline Channel width $(\mu \mathrm{m})$ & 100 & 50 & 100 \\
\hline Flowfield etch step & Isotropic & Anisotropic & Anisotropic \\
\hline
\end{tabular}

It should be noted that the isotropic etching of the crested channels can leave residues of masking material in the ICP RIE chamber as it tends to snap away from the silicon. In the square profile flowfield fabrication this would not happen, as anisotropic etching does not create undercut. For the flowfield etch, a thin photoresist (AZ® 1505) mask suffices for short etch times of about 5 min. We chose a thin photoresist because at $-110^{\circ} \mathrm{C}$ thicker photoresist layers would crack [8]. However, on the backside an aluminum mask is necessary because the through-wafer etch lasts much longer, which a photoresist layer would not survive. This aluminum layer serves also as current collector and electrical contact. While the through wafer etch process parameters are identical to the ones for the flowfield etching, the etch rate is higher; about $7 \mu \mathrm{m} \mathrm{min}{ }^{-1}$ vs. $5 \mu \mathrm{m}$ $\min ^{-1}$, because the etched area is smaller (smaller etch loading).

The MEA is Nafion ${ }^{\circledR} 115$ coated with catalyst using a modification of the thin-film method developed by Wilson and Gottesfeld [9]: carbon supported catalyst (60\% platinum, 40\% carbon, from Alfa Aesar) is mixed with a $5 \mathrm{w}-\%$ Nafion ${ }^{\circledR}$ solution (Aldrich) by magnetic stirring and sonication to produce a catalyst ink. The viscosity of the solution is controlled by adding methanol. This ink is sprayed on the membrane by an air brush through a stencil, to form a uniform, thin catalyst layer on the membrane. After both sides of the membrane have been painted with adequate amount of catalyst material, the membrane is hot-pressed $\left(140^{\circ} \mathrm{C}, 50 \mathrm{kN}, 2 \mathrm{~min}\right)$. The finalized catalyst layer contains approximately $40 \mathrm{w}-\%$ of platinum, $30 \mathrm{w}-\%$ of carbon support and $30 \mathrm{w}-\%$ 
of Nafion ${ }^{\circledR}$ polymer. The loading of platinum is approximately $0.5 \mathrm{mg} \mathrm{cm}{ }^{-2}$ per side.

\section{Measurements}

The micro fuel cells were characterized by clamping them in a custom-built fixture made from two aluminum blocks fitted with threaded gas holes and sockets for electrical contacts. Each block has dimensions of $44 \mathrm{~mm} \times 62 \mathrm{~mm}$ and is $10 \mathrm{~mm}$ thick. A photograph of the fixture connected to gas sources and electric measurement equipment is presented in Fig. 5. The reactant gases were pure, humidified oxygen and hydrogen, flowing at $50 \mathrm{ml} \mathrm{min}{ }^{-1}$ and at a temperature of $\sim 22{ }^{\circ} \mathrm{C}$. The load on the (electric) output of the MFC is swept with an Autolab ${ }^{\circledR}$ PGSTAT100 potentiostat from the maximum (open-circuit voltage, OCV) to $0.1 \mathrm{~V}$, at a rate of $1 \mathrm{mV} \mathrm{s}^{-1}$.

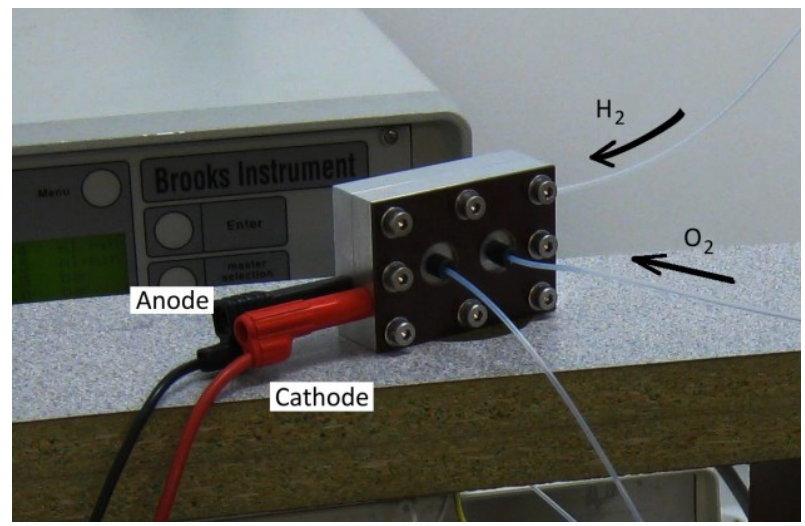

Figure 5: Picture of the measurement setup with the jig clamping a measured MFC.

\section{RESULTS AND DISCUSSION}

All three cell designs were successfully fabricated. The measured current and power output results are summed up in Fig. 6. 

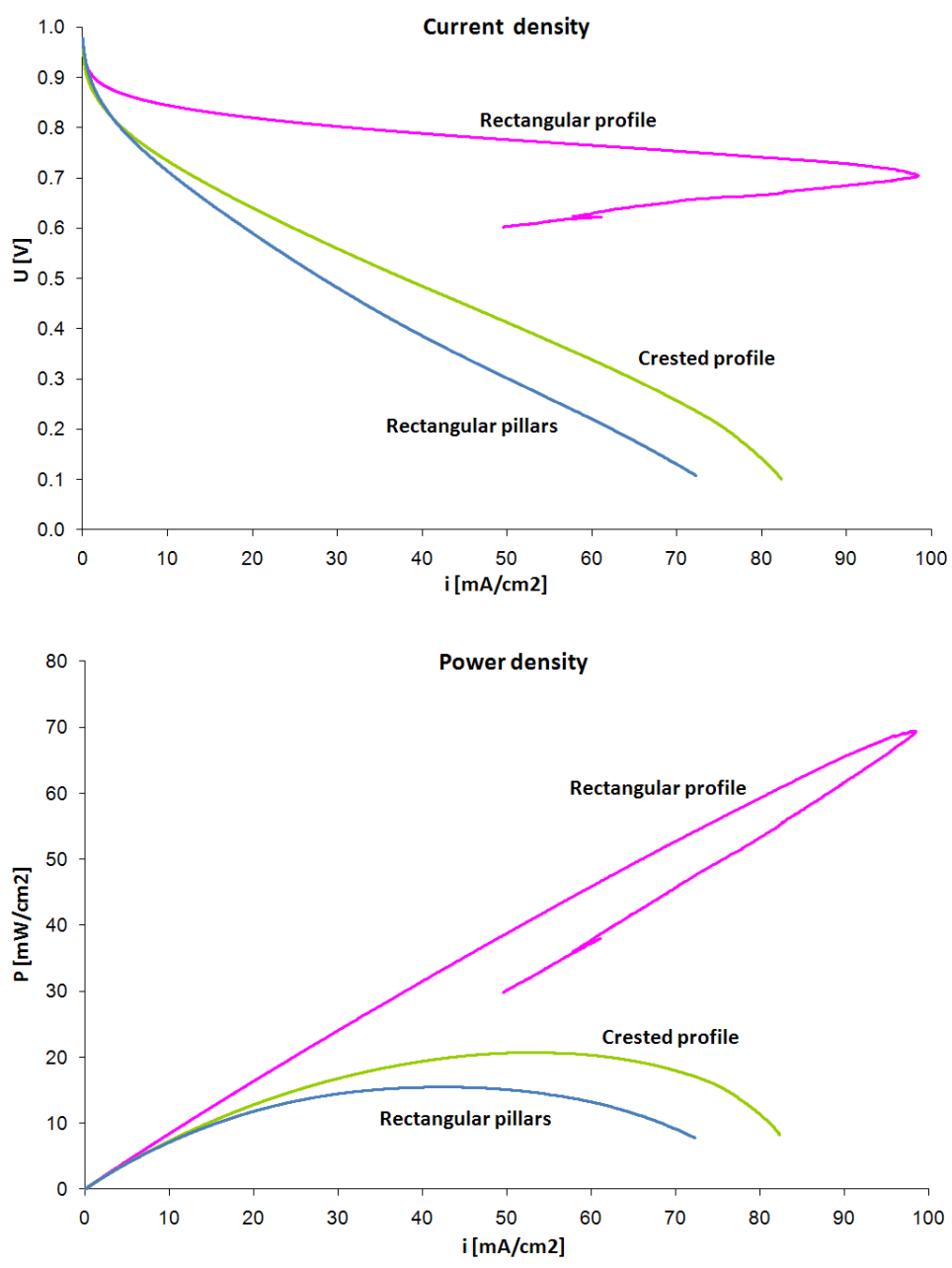

Figure 6: Measured current and power density plots for all 3 types of micro fuel cells.

It is clear from the plots that the square-profile channel fuel cells are the best performance-wise.

This performance is comparable to other hydrogen-fuel silicon MFCs recorded in literature [2] [3] [6] [10] [11]. Our design differs from previous MFCs in using a simple maskless process for forming an integrated silicon nanograss as GDL.

Both straight flow channels and serpentined flow channels with two bends triplicating the flow length (Fig. 4a) have been fabricated and characterized, but no difference in performance was measurable. It can be concluded that enough reactant gas diffuses through the GDL to neutralize any effects of a double-bend serpentine vs. a straight channel flowfield. 
The metallization on the silicon nanograss GDL, whether platinum or chromium, had no significant effect on the performance of the fuel cells. This is a significant finding as it eliminates one noble metal deposition.

The performance difference that the various flow fields exhibit can be explained by different cross sections of the channels and by different contact area between the MEA and the flowfield body. The square pillar flowfield channels have a larger cross section $\left(50 \times 100 \mu \mathrm{m}^{2}\right)$ compared to the straight square channels $\left(30 \times 50 \mu \mathrm{m}^{2}\right)$. This could mean that because of the tighter flow geometry in square channels, reactant gases are pushed more efficiently into the black silicon area, thus improving the performance of these cells. Also, the pillars are wider $(200 \mu \mathrm{m})$ than the ridges between square channels $(50 \mu \mathrm{m})$, which means a longer gas permeation length in black silicon. In the case of crested profile, the cross section is even smaller (less than $10 \times 100 \mu \mathrm{m}^{2}$ ) but in addition only a small area of the flowfield body is in contact with the MEA. Thus, the fewer number of black silicon needles in electrical contact with the MEA could explain the lower performance.

Our rectangular profile fuel cells exhibit an abrupt and permanent degradation at a certain voltage (see the fold-back of the graphs for the square channel MFC on Fig. 6). This was not due to water condensation since after drying the cell, the current density remained under $10 \mathrm{~mA} \mathrm{~cm} \mathrm{~cm}^{-2}$ at all potentials. Post-mortem analysis of the flowfield bodies and MEA (with SEM, AFM and Raman spectroscopy) was inconclusive. The behavior is reproducible, but since the performance is high (much higher current densities could be reached if the degradation did not happen), further research will be done to understand this problem. The devices with crested channel and square pillars did not exhibit this degradation.

Our study confirms the feasibility of simple monolithic silicon MFCs where the GDL is created by etching a single-crystal silicon wafer, such as in [2-6], and improves their designs with the use of silicon nanograss and by a truly maskless fabrication (in contrast to previous silicon micropillars reported by Feng et al. [4]). The quasi-conical shape of the nanograss allows for easy metallization 
via sputtering or evaporation. Most other authors have used a separate GDL, typically carbon fiber or carbon paper as part of a commercial MEA, even though other materials have been proposed, such as sintered steel mesh [12], dendritic platinum deposited by electroplating [11] and chemical vapor deposited (CVD) carbon nanotubes [10]. Separate GDLs in MFCs are used because they are commercially available or because higher performance is achieved with them.

Table 2: Comparison of maximum performances.

\begin{tabular}{|c|c|c|c|c|c|c|}
\hline Max. Current and & \multicolumn{3}{|c|}{ This work: } & Lee et al. & Xiao et al. & Kuriyama \\
Power Densities & Crested & Rect. & Pillars & {$[2]$} & {$[10]$} \\
\hline Current $\left[\mathrm{mA} \mathrm{cm}^{-2}\right]$ & 82.3 & 98.5 & 73 & 38 & 72 & 260 \\
\hline Power $\left[\mathrm{mW} \mathrm{cm}^{-2}\right]$ & 20.7 & 69.2 & 15.4 & 8.13 & 13.7 & 75 \\
\hline
\end{tabular}

Our integrated design ensures good uniformity of electromechanical contact across the assembled device. This improves on the need for external fixtures [10]. The MFCs presented here do not require a noble metal layer for current collection, because the highly-doped, thin silicon substrate itself acts as a current collector. Thick layers of gold [10][11] or platinum [6] are commonly used for this purpose, especially in high-performance MFCs. For instance, Kuriyama et al. [10] evaporated $3 \mu \mathrm{m}$ of gold to act as a current collector. Since the silicon nanograss GDL was fabricated from the same highly-doped silicon bulk as the flowfield and current collector, the conductivity through the GDL is good. While the device in [10] does achieve slightly higher power density than that of ours ( $\left.75 \mathrm{vs} .70 \mathrm{~mW} \mathrm{~cm}^{-2}\right)$ their design requires considerably more materials and levels: glass interconnect structure with metallization, silicon support structure, Au/Ti current collector, copper via metallization with silver paste, MoSi and iron on $\mathrm{SiO}_{2}$ for carbon nanotube (CNT) growth, the CNT GDL itself, etc. In contrast, the simple structure of our membraneflowfield assembly allows for higher compactness and therefore overall thinner cells $(0.8 \mathrm{~mm})$ and higher volumetric power density. With fewer process steps the likelihood for defects decreases and 
we have been able to fabricate fairly large area cells $\left(2.25 \mathrm{~cm}^{2}\right)$ with high yield.

\section{CONCLUSIONS}

A simple, low cost fabrication method has been presented for highly integrated micro fuel cells. The fabricated cells show performance comparable to the best hydrogen MFCs found in literature. The elimination of a separate GDL and current collector has been achieved with silicon nanograss and highly boron-doped silicon main body, respectively. The simplicity of the design allows for easy miniaturization and integration with other MEMS components. The small vertical dimensions make these fuel cells well-suited for stacks in portable devices. The elimination of noble metals for current collection and GDL protection should bring sizable cost savings and open up possibilities for micro fuel cells to penetrate power source markets for portable devices.

\section{ACKNOWLEDGEMENTS}

The authors acknowledge Prof. Valentinas Snitka and Dr. Denys Naumenko, RC for Microsystems and Nanotechnology, Kaunas University of Technology, for the AFM imaging, and the MIDE organization of the Aalto University School of Science and Engineering, for the funding.

\section{REFERENCES}

[1] C. K. Dyer, Fuel cells for portable applications, Fuel Cells Bulletin Volume 2002, Issue 3, March 2002, 8-9

[2] C. Y. Lee, S. J. Lee, Y. C. Hu, W. P. Shih, W. Y. Fan, C. W. Chuang, Integration of silicon micro-hole arrays as a gas diffusion layer in a micro-fuel cell, Int. J. Hydrogen Energy 34 (2009) $6457-6464$

[3] Z. Xiao, G. Yan, C. Feng, P. C. H. Chan, I. M. Hsing, A silicon-based fuel cell micro power system using a microfabrication technique, J. Micromech. Microeng. 16 (2006) 2014-2020 
[4] C. Feng, Z. Xiao, P. C. H. Chan, I. M. Hsing, Lithography-free silicon micro-pillars as catalyst supports for microfabricated fuel cell applications, Electrochem. Commun. 8 (2006) 12351238

[5] S. Aravamudhan, A. R. A. Rahman, S. Bhansali, Porous silicon based orientation indipendent, self-priming micro direct ethanol fuel cell, Sens. Actuators, A 123-124 (2005) 497-504

[6] K. B. Min, S. Tanaka, M. Esashi, Fabrication of novel MEMS-based polymer electrolyte fuel cell architectures with catalytic electrodes supported on porous $\mathrm{SiO}_{2}$ J. Micromech. Microeng. 16 (2006) 505-511

[7] G. Scotti, P. Kanninen, T. Kallio, S. Franssila, Symmetric Fuel Cell with Porous Electrodes, Technical Digest Transducers 2009 (Denver, Colorado, USA, 21-25 June 2009) 1401-1404

[8] L. Sainiemi, S. Franssila, Mask material effects in cryogenic DRIE J. Vac. Sci. Technol. B25 (2007) 801-807

[9] M. S. Wilson and S. Gottesfeld, High Performance Catalyzed Membranes of Ultra-Low Pt Loadings for Polymer Electrolyte Fuel Cells, J. Electrochem. Soc. 139 (1992) L28-L30.

[10] N. Kuriyama, T. Kubota, D. Okamura, T. Suzuki, J. Sasahara, Design and fabrication of MEMS-based monolithic fuel cells, Sens. Actuators, A 145-146 (2008) 354-362

[11] J. Yeom, G. Z. Mozsgai, B.R. Flachsbart, E. R. Choban, A. Asthana, M. A. Shannon, P. J. A. Kenis, Microfabrication and characterization of a silicon- based millimeter scale, PEM fuel cell operating with hydrogen, methanol, or formic acid, Sens. Actuators, B 107 (2005) 882-891

[12] J. Liu, G. Sun, F. Zhao, G. Wang, G. Zhao, L. Chen, B. Yi, Q. Xin, Study of sintered stainless steel fiber felt as gas diffusion backing in air-breathing DMFC J. Power Sources 133 (2004) 175-180 